\title{
Design and Validation of an Open Source 3D Printer Based on Digital Ultraviolet Light Processing (DLP), for the Improvement of Traditional Artistic Casting Techniques for Microsculptures
}

\author{
Jose Luis Saorin ${ }^{1, *} \mathbb{C}$, Manuel Drago Diaz-Alemán ${ }^{2}$, Jorge De la Torre-Cantero ${ }^{1} \oplus$, Cecile Meier ${ }^{2}$ \\ and Ithaisa Pérez Conesa ${ }^{2}$ \\ 1 Engineering Graphic Area, Universidad de La Laguna, Avenida Ánguel Guimerá Jorge s/n, \\ 38204 La Laguna, Spain; jcantero@ull.edu.es \\ 2 Department of Fine Arts, Universidad de La Laguna, Calle Radio Aficionados, s/n, 38320 La Laguna, Spain; \\ madradi@ull.edu.es (M.D.D.-A.); cemeier@ull.edu.es (C.M.); iperecon@ull.edu.es (I.P.C.) \\ * Correspondence: jlsaorin@ull.edu.es; Tel.: +34-922-318002
}

Citation: Saorin, J.L.; Diaz-Alemán M.D.; De la Torre-Cantero, J.; Meier, C.; Pérez Conesa, I. Design and Validation of an Open Source 3D Printer Based on Digital Ultraviolet Light Processing (DLP), for the Improvement of Traditional Artistic Casting Techniques for Microsculptures. Appl. Sci. 2021, 11, 3197. https://doi.org/10.3390/ app11073197

Academic Editor: Namhun Kim

Received: 2 March 2021

Accepted: 30 March 2021

Published: 2 April 2021

Publisher's Note: MDPI stays neutral with regard to jurisdictional claims in published maps and institutional affiliations.

Copyright: (C) 2021 by the authors Licensee MDPI, Basel, Switzerland. This article is an open access article distributed under the terms and conditions of the Creative Commons Attribution (CC BY) license (https:// creativecommons.org/licenses/by/ $4.0 /)$

\begin{abstract}
The adoption of open-source digital manufacturing technologies in small art workshops may improve their competitiveness. Pieces modeled by computer and made with FDM (Fused Deposition Modeling) 3D printers that use PLA (polylactic acid) can be implemented in the procedures of artistic casting. However, models printed by PLA are limited to approximate minimum sizes of $3 \mathrm{~cm}$, and the optimal layer height resolution is $0.1 \mathrm{~mm}$. These sizes and resolutions are not suitable for creating microsculptures used, in many cases, in jewelry. An alternative to solve this limitation, is to use a DMLS (Direct Metal Laser Sintering) 3D printer. However, due to its high cost, it is a technology that is difficult to introduce in small artistic foundries. This work detailed the design and validation of a DLP (Digital Light Processing) 3D printer, using backlit LCD (Liquid Crystal Display) screens with ultraviolet light. Its development is totally "open source" and is proposed as a kit made up of electronic components, based on Arduino and easy to access mechanical components in the market. Most parts can be manufactured in low cost FDM (Fused Deposition Modeling) 3D printers. The result is an affordable, high resolution $(0.021 \mathrm{~mm})$, and open-design printer that can be implemented in artistic contexts.
\end{abstract}

Keywords: artistic casting; electroforming; DLP 3D printer; traditional artistic techniques

\section{Introduction}

Traditional manufacturing techniques used in artistic contexts and associated business models tend to disappear under the pressure of the appearance of mass-produced products that compete in all niche markets, including those traditionally reserved for the work of art. The processes of artistic casting are techniques that can be improved thanks to the new digital manufacturing technologies. The adoption of open-source digital manufacturing technologies in small art workshops can favor their permanence by assuming great advantages such as easy accessibility, low cost, and free modification, adapting to the specific needs of each workshop.

There are several casting processes: sand casting [1], casting with gasifiable molds [2], shell casting [3], the lost wax casting technique [4], and finally, the microfusion [5], a variant of lost wax, which is used to make small detailed parts such as jewelry. On the other hand, in jewelry, there is also a commonly used a technique called electroforming [6]. This technique does not melt the model to turn it into metal, but it is a process that covers the pieces with a very thin metal layer (microns) by using an electric current.

For the creation of molds, and for the processes of lost casting wax, there are 3D printers that produce more detailed objects directly in wax, and these machines are integrated in the industrial foundry and specialize in the processes of creation of jewelry, where they 
have revolutionized the production [7]. However, these printers and their consumables are expensive and, therefore, are not accessible to small craft workshops. Another technology of 3D printing established at industrial levels is "selective laser sintering" (SLS), which builds objects directly in metal. The metallic objects created by this type of 3D printer have approximately 99.99 percent density, and therefore, can be used instead of traditional metal parts in the vast majority of applications [8]. However, the cost of the printed model is also high, so they are not a viable alternative to artistic casting either.

With the appearance of additive manufacturing appears the idea of replacing wax models used in casting with lost wax by computer-designed models manufactured using low-cost 3D printers. To make these models, there are two different materials, the PLA used by the FDM (Fused Deposed Material) printers, and the resin used by the DLP (Digital Light Processing) printers. Computer-designed models allow for greater complexity than can be achieved with the use of traditional hand-modeling techniques $[9,10]$.

This form of construction, where the successive layers of material are placed adapting to the required shapes, produces a laminar texture in the objects that represent a problem for the creation of final pieces. This texture can be smoothed, either by physicochemical processes or by using high resolution printers. In Figure 1, we can see how the layer structure was generated by low-cost printers, where both FDM and SLA are transmitted to bronze. To show this, two different sizes were chosen. The first piece, printed in PLA, was chosen as $10 \mathrm{~cm}$, since it is an average size of those used in sculptural casting using Ceramic Shell Casting procedures. The second piece, printed in photosensitive resin, was chosen as $2 \mathrm{~cm}$ since it is a suitable size for this type of printer and close to the Electroforming processes in microsculpture. On the other hand, it is not frequent to make large pieces $(10 \mathrm{~cm})$ in photosensitive resin for casting, due to the increase in costs and execution time. Nor is it frequent to make very small pieces $(<2 \mathrm{~cm})$ in PLA, due to the problems of FDM type printing that affect the quality of the resulting piece. Besides, with the usual FDM or DLP low-cost printers, it is not possible to print parts smaller than two centimeters without losing all details.

In this article, the construction of an open source DLP type printer made by the FabLab of the University of La Laguna (ULL), which improves the resolution of existing low-cost printers and eliminates the visible laminar texture, is described. This design aims to provide an accessible and modifiable digital manufacturing tool so that small art workshops can use these technologies, through manufacturing spaces such as makerspaces, for the creation of metal pieces less than $2 \mathrm{~cm}$ tall.

It is important to point out that a complementary objective of this work is to provide a new open design, in addition to existing initiatives within the maker's philosophy where developments are accessible by the developer community. The proposed printer is designed to be carried out in digital manufacturing spaces that already have 3D FDM type 3D printing machines or even laser cutting machines (although this last machinery is not essential). 

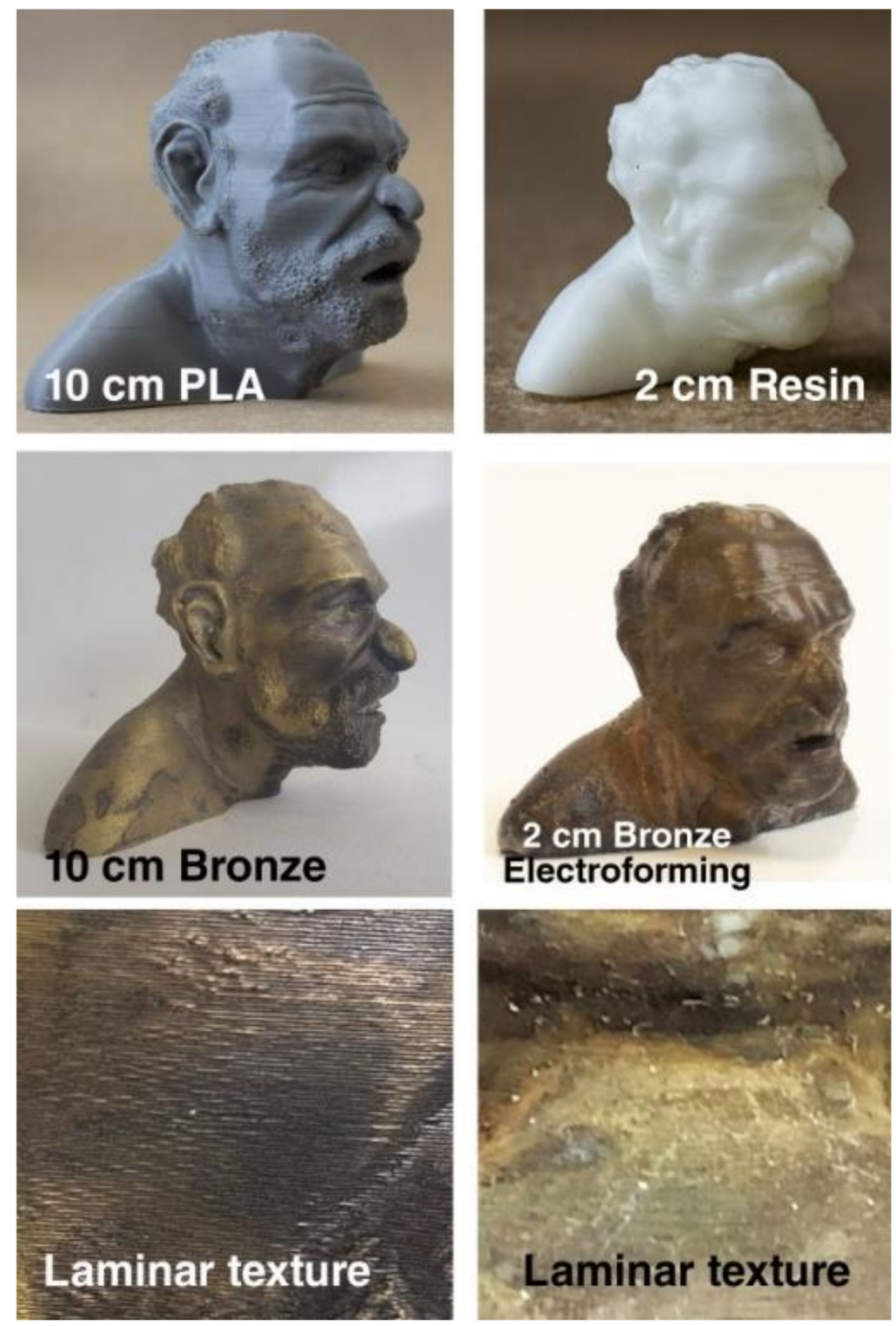

Figure 1. Examples of figures made by PLA (polylactic acid) and resin molds.

\section{Materials and Methods}

2.1. Improving the Resolution of Low Cost 3D Printers

The resolution of 3D printers of the FDM type is conditioned by the manner of manufacturing the objects, by means of stacked layers of molten material. The molten PLA comes out of a nozzle that is normally $0.4 \mathrm{~mm}$, which allows for obtaining a resolution on the $\mathrm{x}, \mathrm{y}$ (width and length) of $0.4 \mathrm{~mm}$ ( 400 microns). The resolution of the $\mathrm{z}$ axis depends on the motors and screws used to move the nozzle on the $\mathrm{z}$ axis. Usually in these printers, the precision can range between a maximum of $0.05 \mathrm{~mm}$ and a minimum of $0.3 \mathrm{~mm}$. This comes to give the height of each layer that is built, so the layers have a resolution of between 50-300 microns.

DLP printers do not deposit a thread, but they manufacture by a light that passes through an LCD screen and hardens a photosensitive resin. In this case, the resolution of the $x$ and $y$ axes depends on the resolution of the screen. Low-cost 3D printers of this type usually have a resolution of $2560 \times 1440$ pixels for a 5.5 -inch screen (often referred to as $2 \mathrm{~K}$ screens). This comes to give a detail of the axes $\mathrm{x}$ and $\mathrm{y}$ of 40 microns. The resolution of the $\mathrm{z}$ axis, as in the PLA printers, depends on the motors and screws used to move the printing table on the $\mathrm{z}$ axis. Most low-cost printers are usually between 35-50 microns (Table 1). 
Table 1. Comparing the resolution of the FDM (Fused Deposition Modeling) and DLP (Digital Light Processing) 3D printers.

\begin{tabular}{ccc}
\hline Resolution & Low Cost 3D Printer FDM & Low Cost 3D Printer DLP \\
\hline Resolution X, Y & 400 microns & 40 microns \\
\hline Resolution $Z$ & $50-300$ microns & $35-50$ microns \\
\hline
\end{tabular}

In order to increase these resolutions, it is proposed to create a printer that improves, on the one hand, the quality of the LCD panel, which influences the resolution X, Y, and on the other hand, the mechanical characteristics of motors and screws that directly influence the resolution on the $\mathrm{z}$ axis. In this research work, we intend to design a DLP printer that can have $30 \%$ more resolution in all three axes. This will be possible in the $\mathrm{x}$ and $\mathrm{y}$ axes, changing the LCD screen with a resolution of $2 \mathrm{~K}$ for a screen with more resolution, in this case $3940 \times 2160$ pixels (they are called $4 \mathrm{~K}$ screens). This provides a resolution of 30 microns on the $x$ and $y$ axis. On the other hand, if a motor with a lower rotation step (0.9 degree Nema17 stepper motor) and a higher quality lead screw is selected (Ball screw), the layer height (z axis) can be improved to $20-25$ microns. It is expected that with these resolutions, the problem of the laminar texture will be solved and parts smaller than two centimeters can be printed (Table 2).

Table 2. Expected resolutions of 3D printer designed.

\begin{tabular}{cc}
\hline Estimated Resolution & DLP 3D Printer FabLab ULL \\
\hline Resolution $X, Y$ & 30 microns \\
\hline Resolutionn $Z$ & $20-25$ microns \\
\hline
\end{tabular}

\subsection{Design of a High Resolution and Low Cost DLP Printer}

The use of better-quality elements directly influences the final price of the printer, so the proposal of this article is to develop a high resolution DLP printer, but whose price is equal to or lowers than the low cost models existing in the market. It is also intended that the printer be open-source, so that any artistic workshop can access the manufacture and modification of it, without additional costs.

DLP printers have traditionally been more expensive than FDM printers; however, in recent years, there have been open-source proposals for this type of printer, as well as low-cost proprietary models. Among the open-source initiatives, the one carried out by Josep Prusa, creator of the Prusai3 FDM printer, stands out. The printer Prusai3 has been, for years, the printer selected as a gateway in the world of digital manufacturing, since it combines a low price with the ability to manipulate and improve the printer itself [11]. In 2018, Prusa Research launched the Prusa SL1 3D resin printer (DLP) with the same philosophy of low cost and open source of its FDM models. This printer is equipped with a high-resolution LCD panel (4K) and its current price is 1699 euros, or 1399 if you buy the kit to assemble it yourself (https:/ / www.prusa3d.es/original-prusa-s11/ accessed on 31 March 2021). On the other hand, there are resin printers that, despite not being open source, can be considered very low cost and, therefore, an interesting option for small art workshops. Among this type of printers is the Wanhao Duplicator 7, manufactured by Wanhao in China. This company, of recent appearance, since it began to sell out of China in the year 2012, has as the main characteristics of its low price and acceptable qualities. In particular, the Wanhao Duplicator 7 model can be obtained for around 500 euros and offers a 2K LCD panel and better resolutions than any FDM printer.

Taking as reference these two options of 3D printers, the Prusa SL1 as an open-source model and the Wanaho Duplicator 7 as a low-cost model, we intend to design an opensource printer that combines both working philosophies, the high resolution of the first and the low cost of the second. To do this, a design is proposed that allows the printer to be built, using methods that can be replicated by any user at a very low cost. Among 
the chosen design options, a repository of 3D pieces of our design will be created to print in PLA with 3D printers of the FDM type. A list of prepared pieces will also be made for its manufacture by cutting machine, free control software will be chosen, and finally, the printer will be provided with low-cost open-source electronics such as Arduino. However, and in order to achieve higher resolution and, therefore, minimize the effect of the laminar texture, the printer will be provided with a $4 \mathrm{~K}$ LCD panel, a 0.9 degree Nema17 stepper motor and a precision ball screw.

For the design of the first functional prototype, the components of the printer have been divided into several categories: parts for 3D printing, parts for laser cutting, electronic components, and mechanical parts purchased. In Figure 2 you can see an image of the CAD (Computer Aided Design) design of the printer.

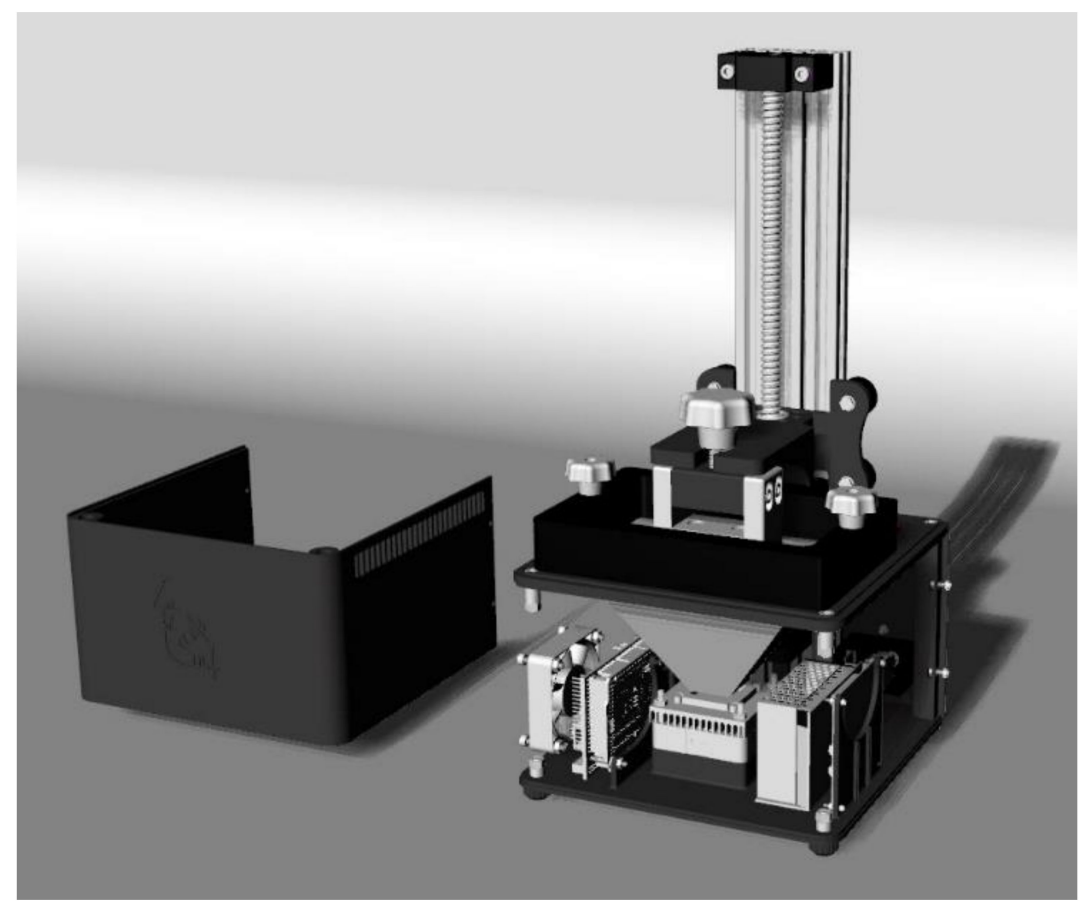

Figure 2. Full design of the high-resolution 3D printer FabLab ULL.

\subsubsection{D Printed Parts}

The design of the pieces has been made with the Rhinoceros application, a modeling software for small businesses and DIY (Do it Yourself) enthusiasts. The pieces had been printed and tested using a prototype to ensure that the design is correct. Once we have the final design of all the printed components, the files (in STL format and in $3 \mathrm{dm}$ format) have been included in a repository so that anyone can access them, both to print them and to modify them. A total of 17 components have been designed, with 31 different pieces that make up all the non-metallic parts of the structure (Figure 3).

After analyzing all the components, one by one, of the DLP printers designed by the FabLab ULL and assuming that they are replicated in a 3D printer type FDM, a printing time of $98 \mathrm{~h}$ and $16 \mathrm{~min}$ is obtained and approximately $1.236 \mathrm{~kg}$ of PLA Basic with a cost estimate of 24.74 euros is used (this price can vary depending on the supplier). These data are shown in detail in Table 3. 

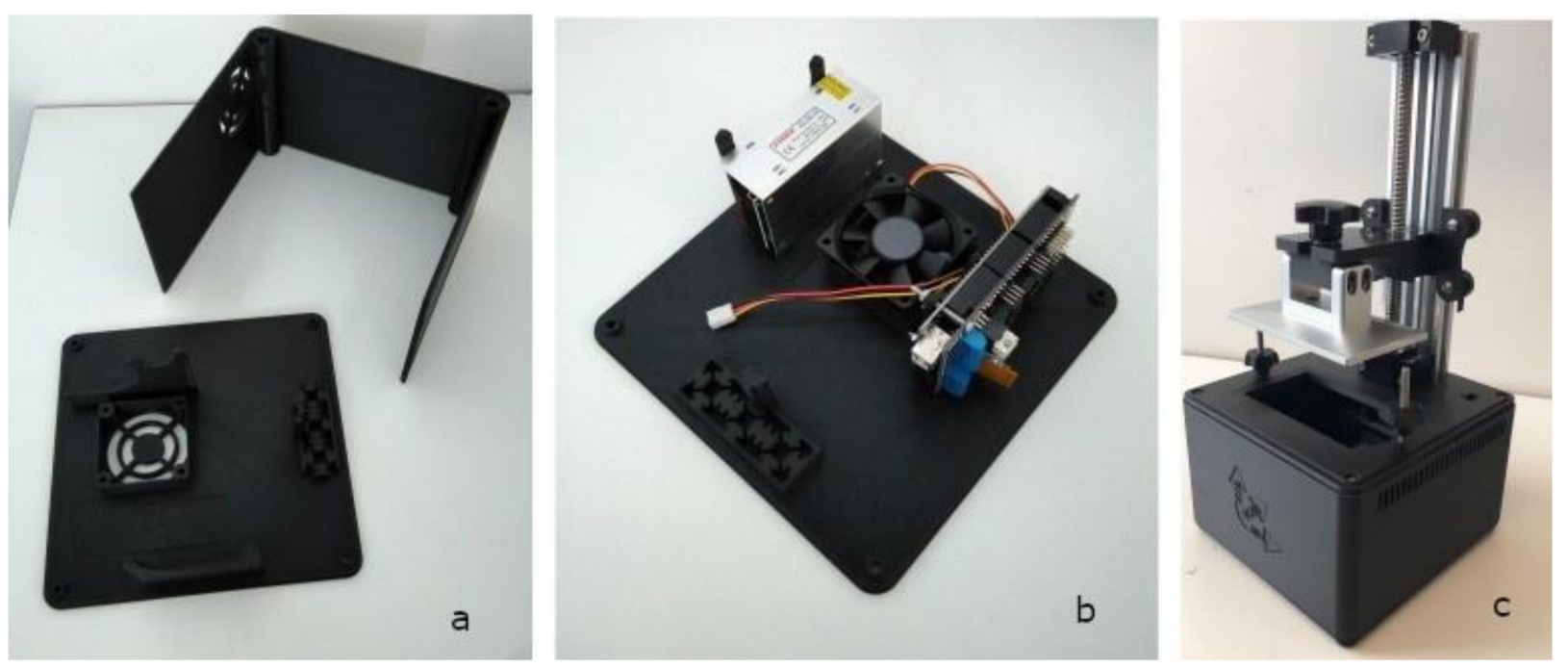

Figure 3. 3D printed parts. (a) Case, (b) Base, (c) All the printed parts.

Table 3. Time and wight of PLA printed parts.

\begin{tabular}{ccc}
\hline Part & Printing Time & Weight in PLA (g) \\
\hline Base & 15 h 3 min & 185.79 \\
\hline Case & 29 h 32 min & 402.53 \\
\hline Motor Support & 1 h 36 min & 20.6 \\
\hline Top Table & 12 h 54 min & 135.21 \\
\hline Arms & 7 h 46 min & 94.9 \\
\hline Wing nut & 1 h 46 min & 22.02 \\
\hline Dowel & 0 h 32 min & 6.51 \\
\hline Handle & 1 h 8 min & 11.94 \\
\hline VAT & 9 h 36 min & 124.75 \\
\hline Print Table & 4 h 56 min & 66.97 \\
\hline Top Cover & $13 \mathrm{~h} 20 \mathrm{~min}$ & 165.06 \\
\hline TOTAL & $98 \mathrm{~h} 16 \mathrm{~min}$ & $1236.28 \mathrm{~g}$ \\
\hline
\end{tabular}

A sample of some of the printed pieces for the creation of the first prototype can be seen in Figure 3. In the image, the assembly of some of the electronic and mechanical elements to validate the design of the pieces can be seen.

\subsubsection{Laser Cutting Parts}

One piece has been designed to be carried out by cutting machines (scissors can be used in case of not having said machinery). The part designed for this procedure is the reflection cover (chute). In the repository the PDF drawings of these parts, developments will be added so that these pieces can be made by any user. The reflection cover will need to be constructed with a reflective material. The estimated cost in material for this piece is around 5 euros.

\subsubsection{Electronic Components}

This section highlights the Arduino Mega 2560 with RAMP 1.4 including the DRV8825 drivers, as well as the LCD Panel $(5.5$ inch $2160 \times 3840)$ with video board. This panel called $4 \mathrm{~K}$ will improve the resolution of the printer in $\mathrm{X}$ and $\mathrm{Y}$ and is the most expensive component of the designed printer, with a cost higher than 200 euros. Also included in this 
section is a 0.9 degree Nema17 stepper motor. This motor allows for the movement in the $\mathrm{z}$ axis to have greater precision and, therefore, a better resolution. The rest of the electronic components include the $405 \mathrm{~nm}$ UV LED (ultraviolet light-emitting diodes), the switches, two fans, two connectors, and a 12 V 5 A power supply. Some of these components can be seen mounted on the base in Figure 3 and the total cost of all of them can be calculated at 278.35 euros.

\subsubsection{Mechanical Parts Purchased}

This section includes those mechanical parts that are purchased by the user, such as V-slot $20 \times 20 \mathrm{~mm}$ extruded aluminum profiles, the flexible shaft coupling, the Ball Screw, four $\mathrm{V}$ wheels, and all the screws necessary for the assembly of the set (Figure 3). The total cost of these pieces amounts to 108.93 euros. This price can be lowered significantly if the screw is installed of a lower quality, such as choosing a Lead Screw $8 \mathrm{~mm}$ Thread $2 \mathrm{~mm}$ (300 mm length) with anti-backlash system (most of the low-cost 3D DLP printer use this screw).

\subsubsection{Control Software}

For the management and preparation of the 3D models, one of the free and opensource programs existing today will be chosen. Some of them are quite frequently used, for example Photonic3D (suitable for developments with Raspberry Pi), or Creation Workshop Slicing and Control Software (suitable for Windows, Mac, etc.). Many low-cost DLP printers recommend the use of some of these programs, and for the prototype developed in the FabLab ULL, Creator Workshop has been chosen. The control software will be included in the documentation repository of the designed printer.

\section{Results}

As a result of the design process of all the parts and the selection of components, the final cost foreseen for the printer amounts to 426.04 euros. This price can vary depending on the component suppliers, although the general trend is for them to drop in price. Table 4 shows the breakdown of the cost of the components according to their classification.

Table 4. Expected cost of the 3D DLP printer.

\begin{tabular}{cc}
\hline Piece & Cost in Euros \\
\hline 3D printed and laser cutting parts & 29.74 \\
\hline Electronic components & 278.4 \\
\hline Mechanical parts purchased & 108.9 \\
\hline Control Software & 0 \\
\hline TOTAL & 426.04 euros \\
\hline
\end{tabular}

An open-source repository has been created where all the 3D models designed are available, as well as the technical documentation of all the electronic and mechanical components. This repository can be accessed at: https:/ / n9.cl/qt612 accessed on 31 March 2021.

Once the 3D printer is designed, assembled, and in operation, we proceed to carry out a calibration test. We have performed the standard "Ameralabs Town" print test for SLA printers. (https:/ / ameralabs.com/blog/town-calibration-part/ accessed on 31 March 2021). The purpose of this test is to calibrate the printing parameters to suit the use and characteristics of the resin. For these tests, "Wanhao Water Washable UV Resin" was used with the following printer parameters: Slice Thickness $0.025 \mathrm{~mm}$, Exposure Layer time $9.000 \mathrm{~ms}$, Bottom Exposure 40.000 ms, Z Lift Distance 4 mm, Z Lift Speed 50 mm/m, and Z Retract speed $50 \mathrm{~mm} / \mathrm{m}$. 
When printing the Ameralabs Town file, ten tests are passed at the same time. In Figure 4, we have included the results of the five tests that we consider most relevant in relation to the $\mathrm{X}-\mathrm{Y}-\mathrm{Z}$ resolution of the printer.
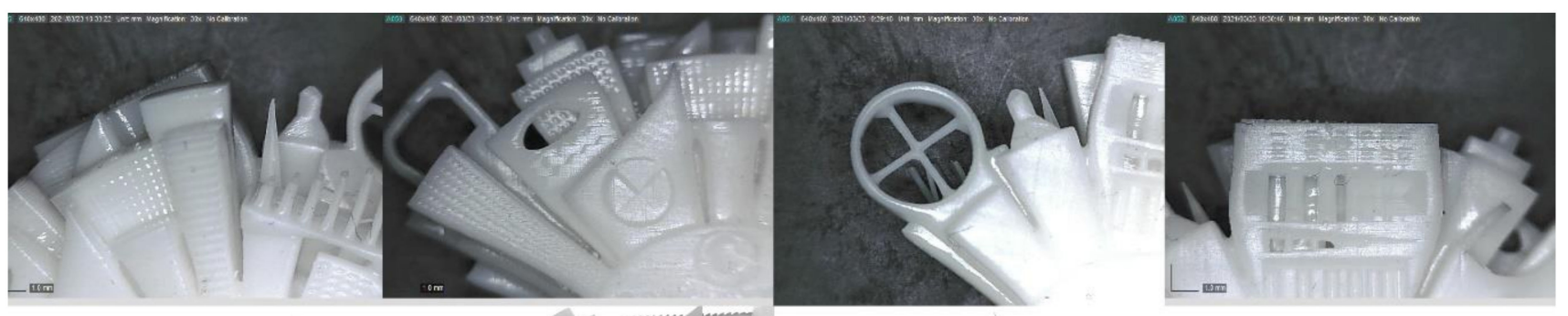

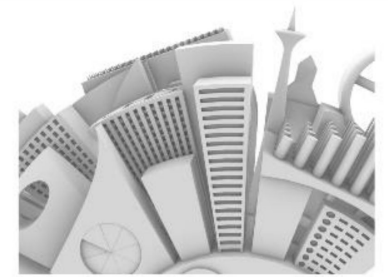

a

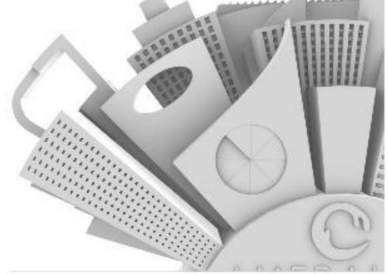

b

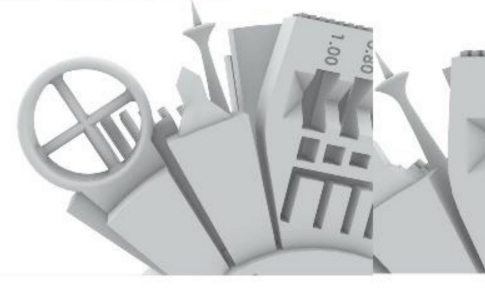

C

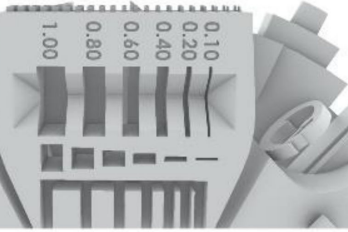

d

Figure 4. Images of the print test (Ameralabs Town) made at $30 \times$. (a) Surface textures, (b) "Alternating deepening plates" test, (c) "Cross-shaped bridges" test, (d) Minimum width of the opening" and "Minimum Height of the opening" test.

In Figure 4, we can see different results of the use of this test, compared with the original CAD file of the test. In Figure $4 \mathrm{a}$, it is observed that the minor details of surface textures are visible. In Figure $4 b$, you can see the result of the "Alternating deepening plates" test. This test is used to reproduce real circumstances of thickness of textures such as texts. We have verified that the eight transitions with steps of $0.025 \mathrm{~mm}$ are unified in four, in such a way that we can deduce that the optimal printing step is $0.05 \mathrm{~mm}$. In Figure 4c, you can see the result of the "Cross-shaped bridges" test. In this test we can observe that although the $0.5 \mathrm{~mm}$ pillars have crossed, we observe some visible light bleed. In Figure $4 d$, you can see the result of the "Minimum width of the opening" test. In this test, we can see that the minimum width of the opening is $0.6 \mathrm{~mm}$. In this same image, we see the "Minimum Height of the opening" test in which a distance of $0.6 \mathrm{~mm}$ is achieved with some deformation. We can also verify that the "Ledges with variable thickness" test has been carried out correctly.

Regarding the $\mathrm{XY}$ resolution, we start from an optical resolution of 30 microns, which is given by the $4 \mathrm{~K} \mathrm{LCD}$ panel. However, and considering the results of the Ameralabs town test, a specific test has been designed to find the maximum real resolution of the printer in these two axes (Figure 5).

In Figure 5a, we can see the designed test that consists of two sets of positive and negative geometries with sizes ranging from $2 \mathrm{~mm}$ to $0.04 \mathrm{~mm}$. In Figure $5 \mathrm{~b}$, we can see the best real results obtained in negative shapes, which corresponds to $0.97 \mathrm{~mm}$ in diameter for the $1 \mathrm{~mm}$ circular shape (in the STL file) and $0.78 \mathrm{~mm}$ side for the square shape of $0.8 \mathrm{~mm}$ (on the STL file). In Figure 5c, we see the best results in triangular and hexagonal shapes circumscribed in circles of 2 and $1.5 \mathrm{~mm}$, respectively. It should be noted that in these figures, the printer has difficulty generating precise angles. In Figure $5 d$, we can see the best results indicated in positive shapes that correspond to the hexagon circumscribed in a circumference of $2 \mathrm{~mm}$ in diameter and a triangle circumscribed in a circumference of $1 \mathrm{~mm}$. In Figure 5e, we can see the results of greater precision of the whole test that correspond to the positive circular shape of $0.6 \mathrm{~mm}$ in diameter whose actual print measurement is $0.62 \mathrm{~mm}$. Likewise, we can observe the best of the resolutions in a square shape that corresponds to $0.6 \mathrm{~mm}$ on each side. 


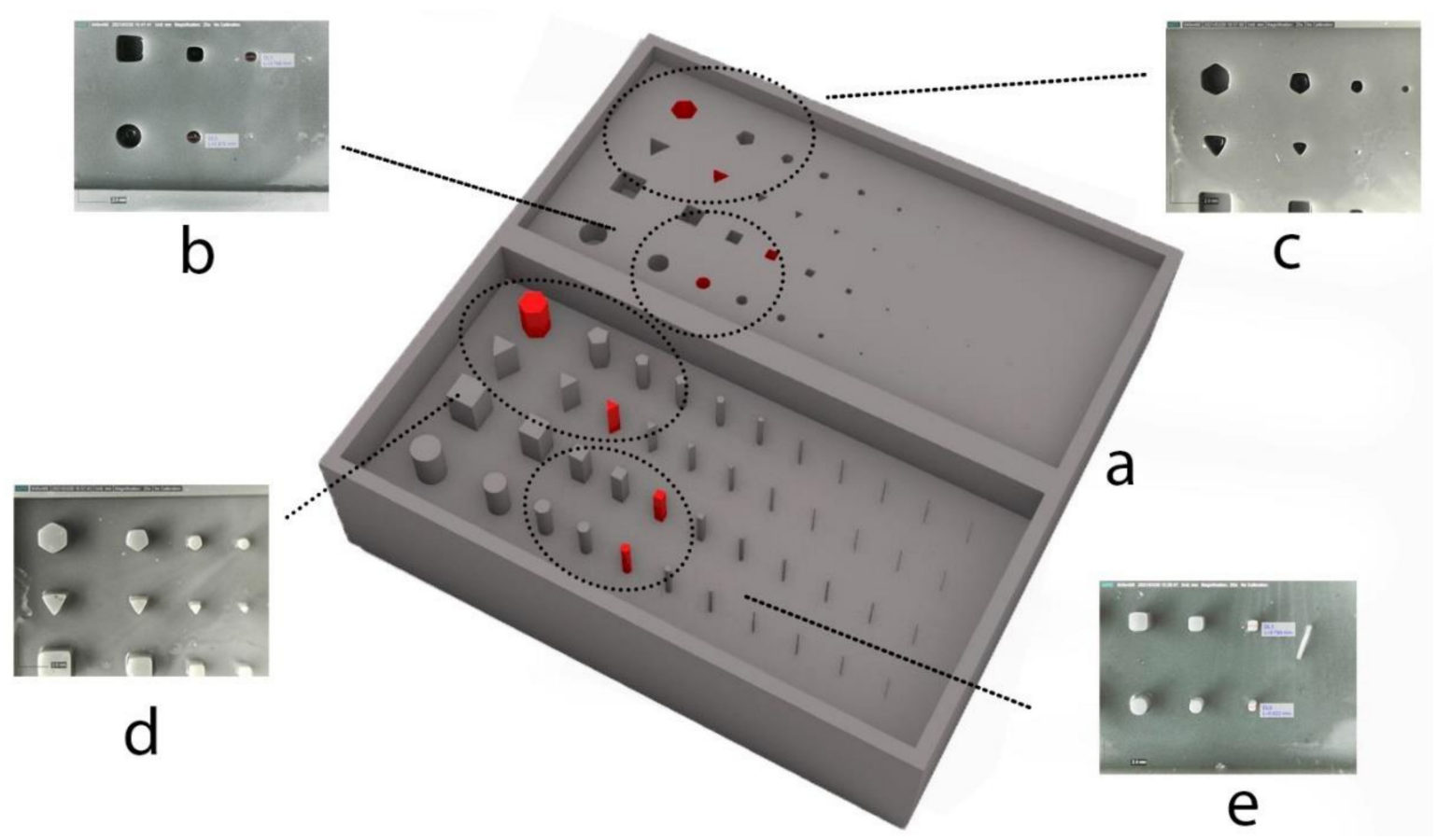

Figure 5. Calibration test results for $X Y$ axes. made at $25 \times$. (a) Designed test, (b) best result for square and circular negative shapes (c) best results in triangular and hexagonal negative shapes, (d) best results for hexagonal and triangular positive shapes, (e) best results for square and circular positive shapes.

These results at first glance do not seem very encouraging. However, as suggested by the creators of the Ameralabs test, it should be mentioned that the result of this type of test depends on the properties of the material as well as the concentration of pigment in the resin. If one uses under-pigmented resin, it is highly possible that due to serious light scattering and light bleeding, just a few or none of the ledges will be formed. Therefore, these results are subject to improvement. The technical specifications of the "Wanhao Water Washable UV Resin" used for these two tests are: Ash $<0.2 \%$, Shore Hardness 75D, Experimental Shrink 3.3\%, Uncolored Reactivity $423 \mathrm{~mJ} / \mathrm{cm}$, Viscosity @ $20{ }^{\circ} \mathrm{C}: 90 \mathrm{CP}$, Density@ $25^{\circ} \mathrm{C}: 1.1 \mathrm{~g} / \mathrm{cm}$, Acidity $<0.31 \mathrm{mg} \mathrm{KOH} / \mathrm{g}$, Water Content $<0.23 \%$, Surface Tension 36.5 Dynes/cm, Tensile Strength 9100 PSI, 6\% Elongation, and Glass Transition Temperature $104{ }^{\circ} \mathrm{C}$. Future tests can be improved by changing print settings and using resins with different properties.

After the calibration, a functional test was performed to determine its real resolution and to be able to compare it with the resolution estimated in Section 2.1. This aspect is important, since the final objective of this printer is to be able to be used in the artistic field for the manufacture of micro-sculptures, that is, for pieces smaller than $20 \mathrm{~mm}$.

Therefore, first, the minimum size of the printable parts was checked while maintaining an adequate level of detail. In Figure 6, you can see the different prints from a size of $30 \mathrm{~mm}$ to a size of $5 \mathrm{~mm}$ in height. It is important to note that all FDM printers and many low-cost DLP printers have trouble printing parts that are $5 \mathrm{~mm}$ in size. For these sizes, the result is usually a printing error, since the PLA or resin cannot be deposited correctly and the figure is unusable.

It is important to note that one of the objectives of the 3D printer is to register the maximum detail of the figures, even in the smallest figures. To check that the level of detail is maintained in all print sizes, a measurement of the ear length of the model used has been made. In the smallest model $(5 \mathrm{~mm}$ ) the length is $1.317 \mathrm{~mm}$ (Figure 7a). It is estimated that below this measure, the quality of the details is lost. In the largest of the models the length of the ear is $7.949 \mathrm{~mm}$ (Figure 7e). 


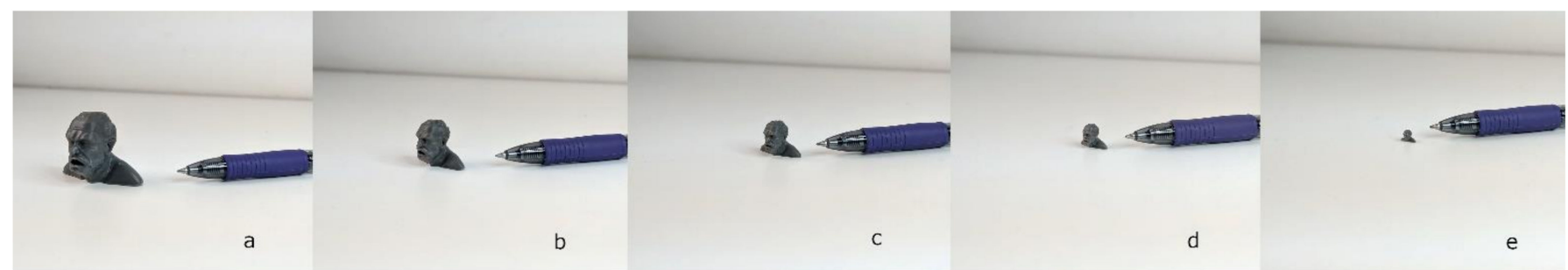

Figure 6. Printed piece with a height of (a) $30 \mathrm{~mm}$, (b) $20 \mathrm{~mm}$, (c) $15 \mathrm{~mm}$, (d) $10 \mathrm{~mm}$, and (e) $5 \mathrm{~mm}$.

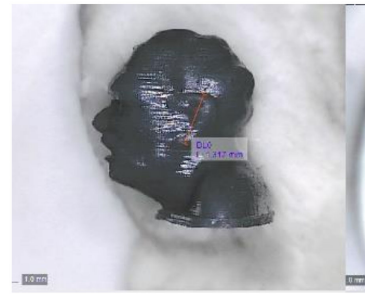

(a)

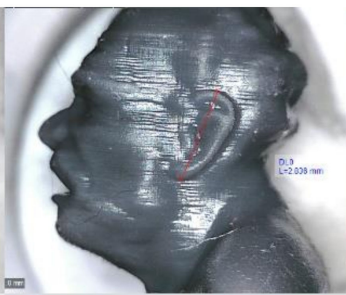

(b)

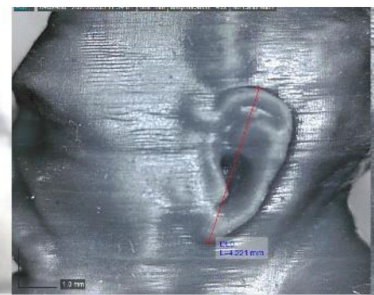

(c)

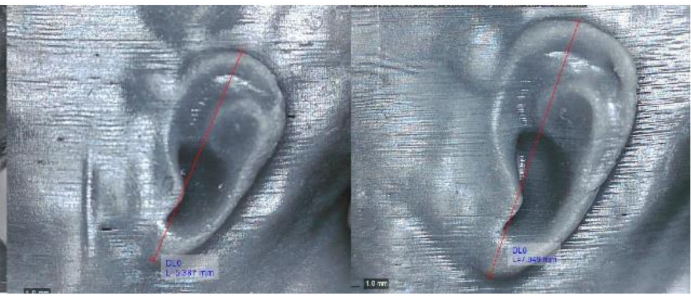

(d)

(e)

Figure 7. From left to right (a-e), ear detail from pieces of $5 \mathrm{~mm}, 10 \mathrm{~mm}, 15 \mathrm{~mm}, 20 \mathrm{~mm}$, and $30 \mathrm{~mm}$ in height.

To measure the resolution in the $\mathrm{z}$ axis, a Dino-Lite microscope with up to 240 magnification has been used where the thickness of each layer can be measured. In Figure 8, we can see, with 200 increases, the results obtained in 10 measurements carried out randomly in the sample. As can be seen, the thickness of each layer presents a certain variability due to the tolerances in the repetitive movements of the $\mathrm{z}$ axis. The values obtained range between 17.942 microns and 24.670 microns. The mean value obtained in the 10 measurements is 21.189 with a standard deviation of 2.079. This mean resolution value is within the range provided in Section 2.1, where a resolution on the $\mathrm{z}$ axis of between 20 and 25 microns was expected.

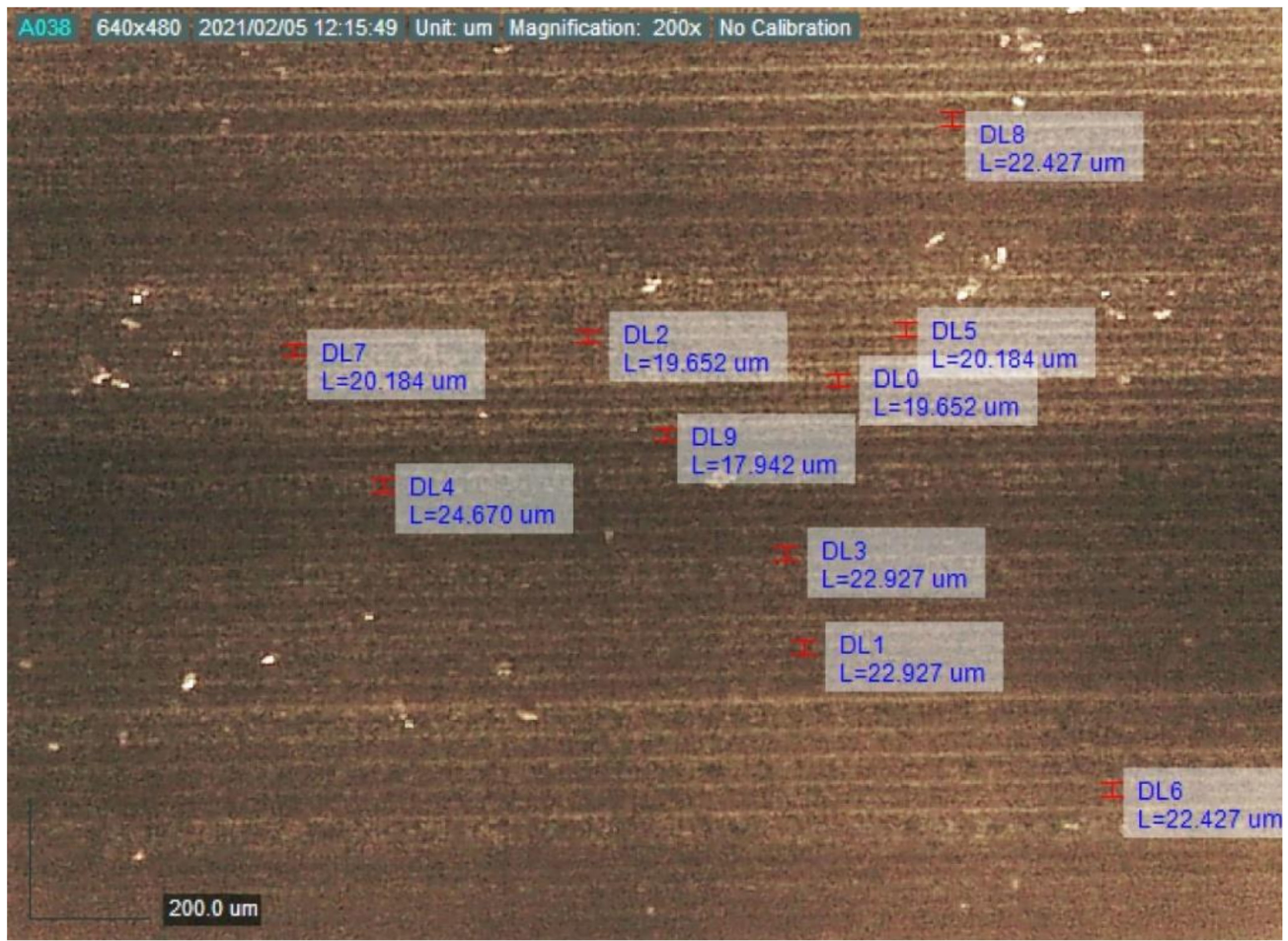

Figure 8. Measurements of the resolution achieved in the $\mathrm{Z}$ axis. 


\section{Conclusions}

With the open-source printer designed in this research work, micro-sculptures up to $5 \mathrm{~mm}$ can be printed without a substantial loss of quality in detail. In this way, the resolutions obtained with FDM printers and low-resolution resin printers are substantially improved. The accuracy (21.18 microns in the $\mathrm{z}$ axis) is superior to low-cost printers that can be purchased for the same price. To achieve this resolution, it is essential to use better quality mechanical components (0.9 step angle NEMA17 stepper motor and M 1204 Ballscrew) than those used in low-cost printers. The increase in costs of these components is offset by the cost reduction in other parts. For example, manufacturing many items with the FDM printer and removing the control panel and USB memory stick reader.

Regarding the $\mathrm{XY}$ resolution, it can be seen that even starting from an optical resolution of 30 microns, thanks to the $4 \mathrm{~K} \mathrm{LCD}$ panel used, the actual resolution obtained is lower. It must be considered that this real resolution depends on the technical specifications of the resins used. For this reason, it would be necessary to carry out tests with resins of different characteristics until obtaining the result closest to the optical resolution of 30 microns.

The cost of the DLP printer designed is similar to the options available in the market for the same resolutions. This price may decrease depending on the component suppliers. Is important to note that to obtain this price, we are assuming that a 3D printer type FDM is previously available. Most digital manufacturing spaces such as makerspaces or Fablab have this type of $3 \mathrm{D}$ printer.

The open-source policy of this development allows any small workshop to have access to this technology and not only test it, but also modify and improve the design according to their own needs. Open-source development allows adaptation to subsequent technological improvements such as, for example, the replacement by new LCD panels of higher resolution $(\mathrm{X}-\mathrm{Y})$.

\section{Future Works}

In future works, we intend to carry out a resolution study in the X-Y axes using lower viscosity resins and different technical specifications. On the other hand, tests of the creation of metallic micro sculptures will be carried out with micro fusion and electroforming processes. We intend to compare runtime and costs with DMLS (Direct Metal Laser Sintering) printers, which build objects directly in metal.

Author Contributions: Conceptualization, J.L.S. and M.D.D.-A.; methodology, M.D.D.-A., I.P.C.; validation, J.D.I.T.-C., M.D.D.-A. and I.P.C.; formal analysis, J.L.S., C.M. and I.P.C.; writing-original draft preparation, J.L.S. and M.D.D.-A.; writing-review and editing, C.M.; visualization, J.D.l.T.-C. and C.M.; project administration, M.D.D.-A.; All authors have read and agreed to the published version of the manuscript.

Funding: This research was funded by the State programme for research, development and innovation aimed at the challenges of society 2017. "Artistic casting of computer-designed micro sculptures through the development of 3D printing techniques based on digital light processing" Reference: HAR2017-85169-R.

Institutional Review Board Statement: Not applicable.

Informed Consent Statement: Not applicable.

Conflicts of Interest: The authors declare no conflict of interest.

\section{References}

1. Guharaja, S.; Haq, A.N.; Karuppannan, K.M. Optimization of green sand casting process parameters by using Taguchi's method. Int. J. Adv. Manuf. Technol. 2006, 30, 1040-1048. [CrossRef]

2. Smith, T.R. Method of Casting. U.S. Patent 3,157,924A, 24 November 1964.

3. Alting, L.; Boothroyd, G. Procesos para Ingeniería de Manufactura; Alfaomega: Ciudad de México, Mexico, 1990.

4. Benavente, J.A. La Fundición a la cera Perdida (Microfusión); Alsina: Barcelona, Spain, 1992.

5. Krekeler, K. Microfusión. Fundición con Modelo Perdido; Gustavo Gili: Barcelona, Spain, 1971.

6. Le Van, M. The Penland Book of Jewelry: Master Classes in Jewelry Techniques; Lark Books: New York, NY, USA, 2005. 
7. Muñoz-Mesa, L.; Sánchez-Trujillo, J.H. El impacto de la impresión 3D en la joyería. Lámpsakos 2017, 1, 89-97. [CrossRef]

8. Kruth, J.P.; Mercelis, P.; Van Vaerenbergh, J.; Froyen, L.; Rombouts, M. Binding mechanisms in selective laser sintering and selective laser melting. Rapid Prototyp. J. 2005, 11, 26-36. [CrossRef]

9. Micallef, J. What's possible with 3D printing? In Beginning Design for 3D Printing; Apress: Berkeley, CA, USA, $2015 ;$ pp. 1-30.

10. Díaz-Alemán, D.; Meier, C.; Pérez-Conesa, I.; Saorin, J.L. Artistic casting of complex 3D printed objects with PLA as an alternative to the wax model. Arte Individ. Soc. 2019, 31, 543-556. [CrossRef]

11. Minetola, P.; Galati, M.; Luliano, L.; Atzeni, E.; Salmi, A. The Use of Self-replicated Parts for Improving the Design and the Accuracy of a Low-cost 3D Printer. Procedia CIRP 2018, 67, 203-208. [CrossRef] 